\title{
Gng12 is a novel negative regulator of LPS-induced inflammation in the microglial cell line BV-2
}

Kelley C. Larson · Maciej Lipko · Michal Dabrowski • Michael P. Draper

Published online: 21 August 2009

(C) Birkhäuser Verlag, Basel/Switzerland 2009

Erratum to: Inflamm. Res.

DOI 10.1007/s00011-009-0062-2

The original version of this article contained a mistake.

The sequence of the author names was incorrect.

The corrected sequence is given below.

Kelley C. Larson, Maciej Lipko, Michal Dabrowski and Michael P. Draper

The online version of the original article can be found under doi:10.1007/s00011-009-0062-2.

K. C. Larson $(\bowtie)$

Galenea Corporation, Cambridge, MA, USA

e-mail: kelleyclarson@yahoo.com

M. Lipko · M. Dabrowski

Nencki Institute of Experimental Biology, Warsaw, Poland

M. P. Draper

Paratek Pharmaceuticals, Boston, MA, USA 